\title{
Intensification of Enzymatic Synthesis of Decyl Oleate Using Ultrasound in Solvent Free System: Kinetic, Thermodynamic and Physicochemical Study
}

\author{
Kajal Jaiswal, Salonee Saraiya, and Virendra K. Rathod* \\ Department of Chemical Engineering, Institute of Chemical Technology, Matunga (E), Mumbai-400019, INDIA
}

\begin{abstract}
The present study evaluates the potential use of ultrasound irradiation to synthesize decyl oleate using Fermase CALB ${ }^{\mathrm{TM}} 10000$ under the solvent-free system (SFS). The optimal condition to achieve a maximum yield of $97.14 \%$ was found to be $1: 2$ oleic acid:decanol ratio, $1.8 \%$ (w/w) enzyme loading, $45^{\circ} \mathrm{C}$ temperature, $200 \mathrm{rpm}$ agitation speed, $50 \mathrm{~W}$ power input, $50 \%$ duty cycle, $22 \mathrm{kHz}$ frequency and reaction time of 25 minutes. The thermodynamic study was done to determine the change in entropy, Gibb's free energy, and change in enthalpy at various temperatures. The experimental results and kinetic study showed that the reaction followed ordered bi-bi model with kinetic parameters as rate of reaction $\left(\mathrm{V}_{\max }\right)=35.02 \mathrm{M} /$ $\mathrm{min} / \mathrm{g}$ catalyst, Michaelis constant for acid $\left(\mathrm{K}_{A}\right)=34.47 \mathrm{M}$, Michaelis constant for alcohol $\left(\mathrm{K}_{B}\right)=3.31 \mathrm{M}$, Inhibition constant $\left(K_{i}\right)=4542.4 \mathrm{M}$ and sum of square error $(\mathrm{SSE})=\mathbf{0 . 0 0 0 3 3 4}$. The application of ultrasound irradiation combined with biocatalyst and the absence of solvent intensified the process compared to the traditional stirring method using hexane as solvent.
\end{abstract}

Key words: decyl oleate, esterification, ultrasound, cosmetic ester, biocatalysis

\section{Introduction}

Over the years, the cosmetic industry has been benefited from using organic compounds in haircare, skincare, fragrances, colors, flavors, and toiletries. Esters, in particular, due to their versatile nature, have found an important place in the global beauty market ${ }^{1}$. Wax esters are extensively used in a range of skincare products such as moisturizers, creams, and hair oils ${ }^{2}$. These esters are produced by the reaction between long-chain fatty acids and alcohols. Moreover, they comprise the main components of Carnauba wax, Candelilla wax, and Beeswax. All three aforementioned products are naturally occurring wax esters ${ }^{3}$. They are characterized as non-toxic, biodegradable, and abundant in nature. However, naturally produced wax esters are not suitable for large scale production and technical applications, which influenced researchers to develop synthetic wax esters ${ }^{4)}$. The compound of focus in this study is decyl oleate, produced from the reaction of decanol and oleic $\operatorname{acid}^{5}$. Decyl oleate possesses low viscosity and hence serves as an excellent lubricant. It is used in moisturizers, creams, sunscreens, lip balms, anti-aging serums, and several makeup products and has become a significant component in beauty products ${ }^{2,5)}$. As the consumers demand greener products, biocatalysis is preferred over chemical ones to synthesize wax esters. The chemical catalytic scheme suffers from disadvantages like requirement of harsh reaction conditions, massive down-streaming method, formation of side product, and recyclability issue ${ }^{6}$. To overcome these chemical catalysis limitations, there is a need to employ green and environmental-friendly bio-catalytic process ${ }^{4}$. The most profoundly used class of biocatalyst for the synthesis of various organic compounds is the lipase enzymes. They have immense importance in the biocatalysis field as they have the potential to catalyze numerous organic synthesis in non-aqueous system ${ }^{4)}$. Lipases are attracting a great deal of interest among researchers and industrialists as they own extensive substrate stereoselectivity, chemoselectivity, and regioselectivity. The use of

Abbreviations: V: Rate of reaction, Vmax: Maximum rate of reaction, Ka, Kb: Apparent Michaelis Menten constant for acid and alcohol respectively, Ki: Inhibitory constant, K: Rate constant, Kb: Boltzmann constant, A: Pre-exponential factor, Ea: Energy of activation $(\mathrm{J} / \mathrm{mol}), \mathbf{T}$ : Temperature $(\mathrm{K}), \mathbf{R}$ : Universal gas constant $(\mathrm{J} / \mathrm{mol} \mathrm{K})$, h: Planck's constants, $\Delta \mathbf{G}$ : Change in Gibbs free energy, $\mathbf{\Delta H}$ : Change in enthalpy, $\mathbf{\Delta S}$ : Change in entropy

\footnotetext{
*Correspondence to: Virendra K. Rathod, Department of Chemical Engineering, Institute of Chemical Technology, Matunga (E), Mumbai-400019, INDIA

E-mail: vk.rathod@ ictmumbai.edu.in

Accepted December 10, 2020 (received for review August 25, 2020)

Journal of Oleo Science ISSN 1345-8957 print / ISSN 1347-3352 online

http://www.jstage.jst.go.jp/browse/jos/ http://mc.manusriptcentral.com/jjocs
} 
lipase further offers various benefits that include mild reaction conditions, requirement of low energy, minimal waste disposal, sustainable E-Factor, biocatalyst reusability, and less by-product generation ${ }^{4,7}$. The broad adaptability of lipase catalysis in the synthesis of a cosmetic group of esters still needs to be explored and investigated. But, the use of free lipase is usually limited because of quick deactivation, inadequate stability, and reusability. However, lipase immobilized over solid support can enhance the performance of lipase effectively ${ }^{8,9)}$. Immobilization methods can sustain the activity of lipase and improve its stability and can also intensify enzyme characteristics, such as selectivity and specificity. There are several reports in the literature on the advantages of enzyme immobilization ${ }^{10,11}$. It was effectively used to catalyze the synthesis of various cosmetic esters in SFS, and the enzyme was reused for several runs $^{12)}$. The optimization study of the enzymatic synthesis of cetyl oleate ester using a fungal lipase from immobilized Candida antarctica has been studied ${ }^{13)}$. The esterification is a thermodynamically controlled reaction, and one of the products formed is water ${ }^{14)}$. It is primarily performed in low water activity systems because water, being a side product of the reaction, can drive the equilibrium towards hydrolysis. Thus, the use of molecular sieves to adsorb the excess of water in the reaction has been listed as a powerful way to enhance the enzyme performance ${ }^{14)}$.

The immobilization method helps to lower the cost of process, but the use of a solvent in biocatalytic synthesis is still an issue ${ }^{15)}$. Although organic solvents offer various advantages to the enzyme-catalyzed reactions, their application in the commercial sector is not acceptable ${ }^{2,6)}$. Organic solvents are the main cause of volatile organic compounds, affecting the environment and threat to human health. The use of organic solvents requires high-cost treatment operations, costly reactors, and tools, and have an inhibition impact on the lipase ${ }^{6)}$. The reactions performed under solvent-free system can help to overcome these disadvantages. Moreover, higher selectivity and easy purification are important advantages of solvent-free system ${ }^{16}$. The lipasecatalyzed synthesis of the decyl oleate required $1 \mathrm{~h}$ to reach equilibrium with $2.5 \%$ enzyme loading and $n$-hexane as solvent $t^{5)}$. Despite its favorable results, factors such as time and enzyme activity could be improved to provide a more efficient decyl oleate production. There have been very few studies in the literature on the synthesis of cosmetic esters using lipase as a catalyst under the solventfree system.

Although immobilization and SFS help to improve the enzyme's performance, several researchers have employed the process intensification tool like ultrasound irradiation to improve the rate of reaction ${ }^{16,17)}$. The ultrasound waves move through liquid media and create cavitation, which results in the formation of microbubbles in the reaction system. These bubbles implode energetically with high temperature and pressure ${ }^{17)}$. The powerful stream of liquid ruptures the boundary to produce intense shock waves that diffuse through the fluid, which causes proper mixing and severe turbulence. Therefore, the ultrasound irradiation is supposed to overcome the mass transfer limitation by reducing the activation energy and increase the rate of reaction ${ }^{2,17)}$. The ultrasound method is also regarded as a greener approach because of high-caliber performance, low-cost requirements, and reliable reusability. It has also been noted that the water present in the esterification reaction decreases the conversion due to the hydrolysis of the product, which can be overcome using molecular sieves ${ }^{18)}$. Molecular sieves will adsorb the water from the bulk of solution while water present inside the pores may build a layer on the enzyme and unfavorably influence the reaction ${ }^{19}$. The cavitation produced because of ultrasound further creates turbulence inside the pores and does not permit water to build a layer and affect the reaction ${ }^{18,20)}$. Over the years, cosmetic and pharmaceutical industries have rapidly incorporated this ultrasound technique for various enzyme-catalyzed reactions ${ }^{2}$.

In the current study, the synthesis of decyl oleate was carried out using enzyme in the presence of ultrasound under solvent-free system. In this work, Fermase $\mathrm{CALB}^{\mathrm{TM}} 10000$ was used as a biocatalyst as it offers higher activity, good stability, and excellent selectivity. Fermase $\mathrm{CALB}^{\mathrm{TM}} 10000$ is an enzyme catalyst of Candida antarcti$c a$ lipase B immobilized on polyacrylate beads. The research work includes experimental analysis to optimize various operating parameters such as time, enzyme loading, molar ratio, temperature, speed of stirring, duty cycle, power, and frequency. The bi-substrate kinetic models were applied to the experimental data to determine various kinetic parameters, followed by the thermodynamic study of the reaction and determination of physicochemical properties of the ester.

\section{Materials and Methods}

\subsection{Materials}

Fermenta Biotech Ltd., Mumbai supplied Fermase $\mathrm{CALB}^{\mathrm{TM}} 10000$; a commercial Candida antarctica lipase B. Molecular sieves were bought from M/s Merck Ltd., Mumbai. Decyl alcohol and oleic acid were obtained from SDFCL Ltd., Mumbai, while ethanol, potassium hydroxide, and Phenolphthalein indicator $(\mathrm{AR})$ were obtained from Thomas Baker Pvt. Ltd., Mumbai.

\subsection{Methods}

\subsubsection{Conventional esterification reaction}

The synthesis was carried out in a four baffled glass reactor with $50 \mathrm{~mL}$ capacity equipped with an overhead three-bladed turbine impeller for agitation. A reaction ex- 
periment was performed using oleic acid, decanol, and Lipase Fermase CALB as a biocatalyst. After adding the substrates, the lipase enzyme was fed into the reactor to initiate the reaction, followed by the addition of the molecular sieves. The temperature of the reactor was controlled using a water bath and temperature control system. To monitor the progress of the reaction, the samples were collected periodically for analysis.

\subsubsection{Ultrasound mediated esterification reaction}

The ultrasound-mediated reaction was performed in an ultrasonic thermostatic water bath. The esterification was carried out in a $50 \mathrm{~mL}$ flat-bottom glass reactor with four baffles and agitation provision using an impeller. The glass reactor was positioned in a water bath at the elevation of 2 $\mathrm{cm}$ over the base as per the published data ${ }^{21)}$. The temperature of the water bath was maintained constant by a heater or by adding cold water. The set up is equipped with a transducer working at two frequencies of $25 \mathrm{kHz}$ and 40 $\mathrm{kHz}$ and the highest power rating of nearly $200 \mathrm{~W}$. In a typical procedure, oleic acid:decanol were taken in 1:2 molar ratio and transferred inside the glass reactor to make up the overall volume to $15 \mathrm{~mL}$ without solvent. Then, $3.5 \%(\mathrm{w} / \mathrm{w})$ enzyme and $1 \%(\mathrm{w} / \mathrm{w})$ molecular sieves were introduced into the reaction mixture. The temperature of reaction mixture, stirring speed, ultrasound power, frequency, and duty cycle were set, and the reaction was continued until the equilibrium was achieved. A minimal amount of samples was drawn at a different interval of time and analyzed by the titration method to determine unreacted oleic acid in the reaction mixture in terms of its acid value.

\subsubsection{Titrimetric analysis}

The percentage conversion of decyl oleate was determined in terms of acid value. The reaction mass $(0.1 \mathrm{~g})$ was taken in the conical flask, and the reaction was quenched by adding ethanol. It was titrated against alcoholic $\mathrm{KOH}$ $(0.01 \mathrm{~N})$ by adding phenolphthalein indicator, and the residual oleic acid in the reaction mass was calculated. The samples were titrated thrice for correctness, and the percent conversion was calculated as follow:

$\frac{\text { VolumeofKOHutilised (withoutenzyme) -VolumeofKOHutilised (withenzyme) }}{\text { VolumeofKOHutilised (withoutenzyme) }} \times 100$

2.2.4 Purification and characterization of decyl oleate

The reaction mass was filtered through Whatman filter paper to separate the reaction volume from lipase particles and molecular sieves. It was washed several times, and the washed enzyme and molecular sieves were then dried in an oven. The enzyme was separated from molecular sieves by physical separation, and the enzyme was then stored in the desiccator. The reaction mass consisted of the desired product decyl oleate, some unreacted decyl alcohol, and oleic acid. The oleic acid was neutralized using a saturated sodium hydroxide solution. Fourier Transfer Infrared Spectroscopy (FT-IR) (Shimadzu, Miracle 10, and IR Affinity-1S) was used to identify the functional groups in the product.

2.2.5 Determination of physicochemical properties of decyl oleate

The physicochemical characteristics of wax ester, like acid value, saponification value, specific gravity, and refractive index, were estimated as per the standard AOCS methods Te 1a-64, Tl 1a-64, To 1b-64, and Tp 1a-64, respectively. Pour points were determined as per D97 methods. A spreading value test was conducted on a synthetic membrane. The viscosity was estimated using Canon Fenske reverse flow viscometer.

2.2.6 Statistical analysis

Statistical analysis is an essential aspect to interpret and analyze the data collected from experiments. The practical study of wax ester was conducted in triplicate and shown as the mean of three replicate values, and the error bars presenting standard deviations (means $\pm \mathrm{SD}$ ). The $p$-value less than $0.05(p<0.05)$ is essential and statistically accepted.

\section{Results and Discussions}

The optimization, kinetic, and thermodynamic studies were performed for decanol and oleic acid reaction with the immobilized lipase enzyme in the presence of ultrasound irradiation under solvent-free system, as shown in Scheme 1.

\subsection{Effect of temperature}

The temperature influences the activity and stability of the enzymes and also affects the rate of reaction. It is a significant parameter that improves the catalytic synergism

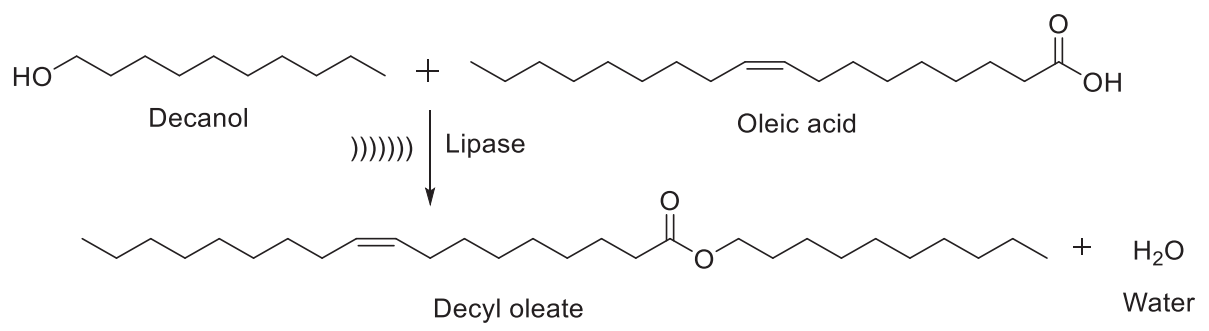

Scheme 1 Synthesis of decyl oleate. 
with the substrates and immobilized enzyme and also decreases the viscosity of the medium ${ }^{13)}$. However, at a high temperature, the enzymes may become inactivated due to the distortion of the enzyme structure ${ }^{2,17)}$. Although the immobilized enzyme exhibited enhanced thermal stability, it is essential to determine the optimum temperature for the reaction ${ }^{15)}$. The impact of temperature was evaluated at different temperatures varying from $30^{\circ} \mathrm{C}$ to $45^{\circ} \mathrm{C}$ by maintaining the other operating parameters fixed at $1.8 \%$ enzyme and 1:2 oleic acid:decyl alcohol mole ratio. It is noticed from Fig. 1 that the conversion increased rapidly from $63.41 \%$ to $97.74 \%$, with a rise in temperature from $30^{\circ} \mathrm{C}$ to $40^{\circ} \mathrm{C}$. Thus, in the presence of ultrasound irradiation, a maximum conversion of $97.74 \%$ was achieved at $40^{\circ} \mathrm{C}$. At optimal temperature, the formation of a bubble is less, but they implode with an energetic force that causes effective transfer of substrate molecules on the active enzyme sites ${ }^{20)}$. A similar impact of temperature on the enzyme-catalyzed synthesis of D-isoascorbyl palmitate under the influence of ultrasound irradiation has also been reported $^{21)}$. However, an increase in the temperature further to $45^{\circ} \mathrm{C}$ decreased the conversion due to decrease in cavitation intensity above $40^{\circ} \mathrm{C}$. It must be noted that the generation of the bubble is high at a higher temperature, but the bubble implodes with low intensity leading to a decrease in the mass transfer and low conversion ${ }^{22,23)}$. Thus, $40^{\circ} \mathrm{C}$ was estimated to be the optimum temperature for the enzymatic reaction and employed for further experiments.

The energy of activation is the minimum amount of

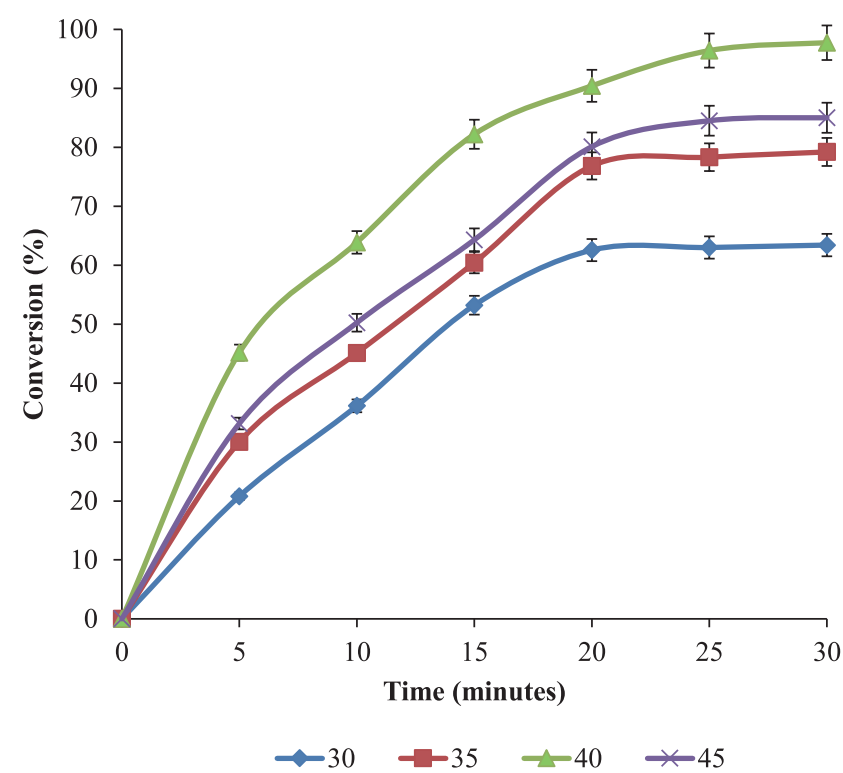

Fig. 1 Effect of temperature on conversion. Reaction condition: time- $25 \mathrm{~min}$, enzyme dose- $1.8 \% \mathrm{w} / \mathrm{w}$, oleic acid:decyl alcohol ratio- 1:2, ultrasound power- $50 \mathrm{~W}$, ultrasound frequency- $22 \mathrm{kHz}$, speed of agitation- $200 \mathrm{rpm} \&$ duty cycle- $50 \%$. energy needed to transform a steady species into a reactive species, and it also indicates the speed of esterification. The Arrhenius equation presents a link between the reaction rate constant $(\mathrm{k})$, absolute temperature $(\mathrm{T})$, and the activation energy (Ea) as:

$$
\ln \mathrm{k}=-\mathrm{Ea} / \mathrm{RT}+\ln \mathrm{A}
$$

Where A represents the frequency factor; $\mathrm{k}$ represents reaction rate constant; $\mathrm{R}$ denotes the molar gas constant $(8.314 \mathrm{~J} / \mathrm{mol} / \mathrm{K})$; Ea represents activation energy $(\mathrm{kJ} / \mathrm{mol})$, and $\mathrm{T}$ indicates the temperature $(\mathrm{K})$. The study was carried out with optimum values of molar ratio, enzyme dose, agitation speed for four different temperatures. The Arrhenius graph of $\ln (\mathrm{k})$ vs. reciprocal of temperature $(1 / \mathrm{T})$ was plotted to evaluate the energy of activation for the synthesis of decyl oleate under the influence of ultrasound, as shown in Fig. 2. For the decyl oleate synthesis in the mechanical stirring system, the activation energy was determined as $16.24 \mathrm{kcal} / \mathrm{mol}^{5)}$. Whereas the activation energy Ea determined in the presence of ultrasound irradiation is $9.12 \mathrm{kcal} / \mathrm{mol}$. The lower value of the energy of activation Ea for the decyl oleate synthesis in the presence of ultrasound showed that ultrasound irradiation assists in increasing the reaction rate by overcoming mass transfer resistance ${ }^{24)}$. The energy of activation value estimated for the lipase-catalyzed synthesis of decyl oleate lies in the range listed in the literature study ${ }^{25)}$.

\subsection{Effect of enzyme loading}

The other operating parameter affecting the reaction rate is enzyme loading that considerably influences the whole biocatalytic reaction economic feasibility. The synthesis of decyl oleate esters involves long-chain alcohols

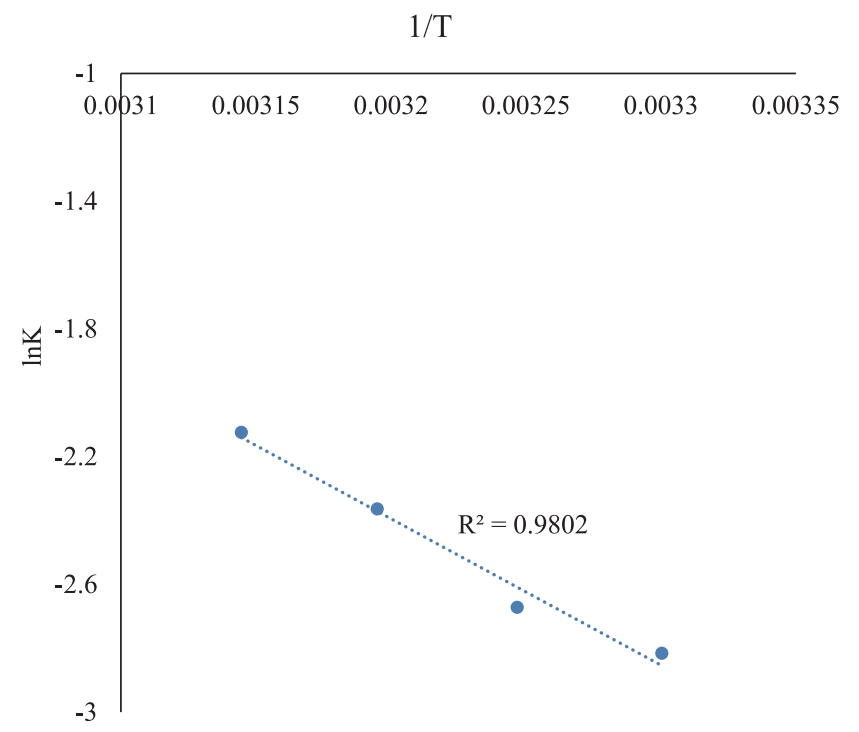

Fig. 2 Arrhenius plot for esterification of decyl oleate for obtaining the Activation energy. 
and long-chain fatty acids, which will reduce the mass transfer because of the increased viscosities in the medium. Also, a very high amount of enzymes is not advised in the reaction as the enzymes can agglomerate, change its activity, and increase the viscosity of media ${ }^{26)}$. To examine the influence of the enzyme amount in the presence of ultrasound, several batches were carried out by changing the enzyme loading from $1.0 \%(\mathrm{w} / \mathrm{w})$ to $2.0 \%(\mathrm{w} / \mathrm{w})$ at $1: 2$ oleic acid:decyl alcohol molar ratio and $40^{\circ} \mathrm{C}$ temperature and the results are illustrated in Fig. 3. It was seen that the only cavitation effect is not enough to carry out the esterification and the use of enzyme was also essential to catalyze the reaction. The continuous generation and subsequent implode of the bubble is required to overcome the mass transfer limitation and improve further collisions ${ }^{27)}$. An increase in the conversion from $63.01 \%$ to $97.44 \%$ was noted, with the rise in the enzyme dose from $1.0 \%(\mathrm{w} / \mathrm{w})$ to $1.8 \%(\mathrm{w} / \mathrm{w})$. The high amount of enzyme supported the active enzyme-substrate complex formation, which led to a maximum conversion. The conversion recorded for the high enzyme dose above $1.8 \%(\mathrm{w} / \mathrm{w})$ showed a marginal increase in percent conversion. A similar type of conversion trend was seen for the enzyme-catalyzed synthesis of cetyl caprate wax ester $^{4)}$. Furthermore, the ultrasound-assisted method gave $97.44 \%$ conversion in 25 minutes with $1.8 \%$ $(\mathrm{w} / \mathrm{w})$ enzyme dose in a solvent-free system as compared to the conventional technique, which gave $96.5 \%$ in $1 \mathrm{~h} \mathrm{re-}$ action time using hexane as a solvent ${ }^{5)}$. Therefore considering the economic practicability, the surplus use of the enzyme was restricted, and all the experiments were

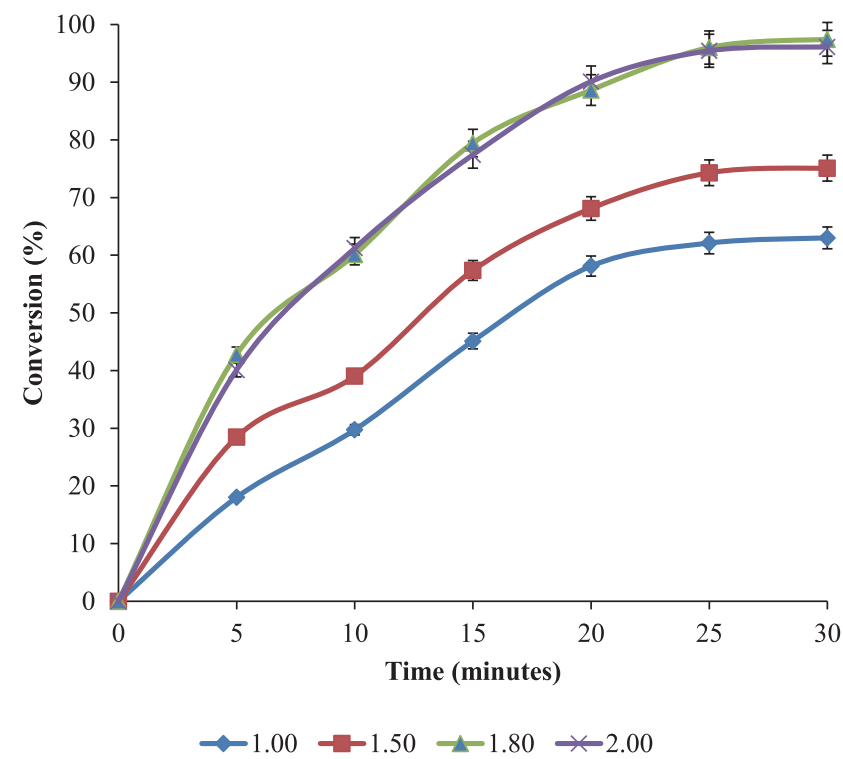

Fig. 3 Effect of enzyme loading on conversion. Reaction condition:time- $25 \mathrm{~min}$, temperature- $45^{\circ} \mathrm{C}$, oleic acid:decyl alcohol ratio- 1:2, ultrasound power- 50 W, ultrasound frequency- $22 \mathrm{kHz}$, speed of agitation- $200 \mathrm{rpm} \&$ duty cycle- $50 \%$. carried out with $1.8 \%(\mathrm{w} / \mathrm{w})$ enzyme concentration.

\subsection{Effect of molar ratio}

The impact of the molar ratio is the most significant parameter that influences conversion. The molar ratio is used to understand the effect of reactants on the activity of enzyme and the rate of esterification reaction. The impact of oleic acid:decanol ratio on the percentage conversion was investigated at different molar ratios varying from 1:1 to $1: 3$ and presented in Fig. 4. It is seen that the percentage conversion increased from $63.45 \%$ to $97.14 \%$ as the amount of alcohol was increased from 1:1 to $1: 2$, and an increase in the amount of alcohol to 1:3, decreased the conversion to $83.54 \%$. A maximum conversion of $97.14 \%$ was achieved when the ratio of 1:2 was used in the reaction. Thus it can be inferred that a higher volume of decyl alcohol decreases the percent conversion. It can be attributed to the polar nature of alcohol as it contains $-\mathrm{OH}$ group. Hydrophilic alcohol interacts with the aqueous layer on the exterior of the lipase that may change the conformation of the lipase and lead to inhibition and decreases the activity. The polar nature of alcohol and the interaction may also cause stripping of the essential water molecule from the enzyme surface ${ }^{28)}$. Besides, it was noticed that the cavitation phenomena gave a higher conversion of $97.14 \%$ at 1:2 oleic acid:decanol molar ratio as compared to the conventional approach. Thus, higher conversion due to cavitation and mass transfer effect was observed due to the proper mixing of the reaction mass in the solvent-free medium without disrupting the micro-environment of the

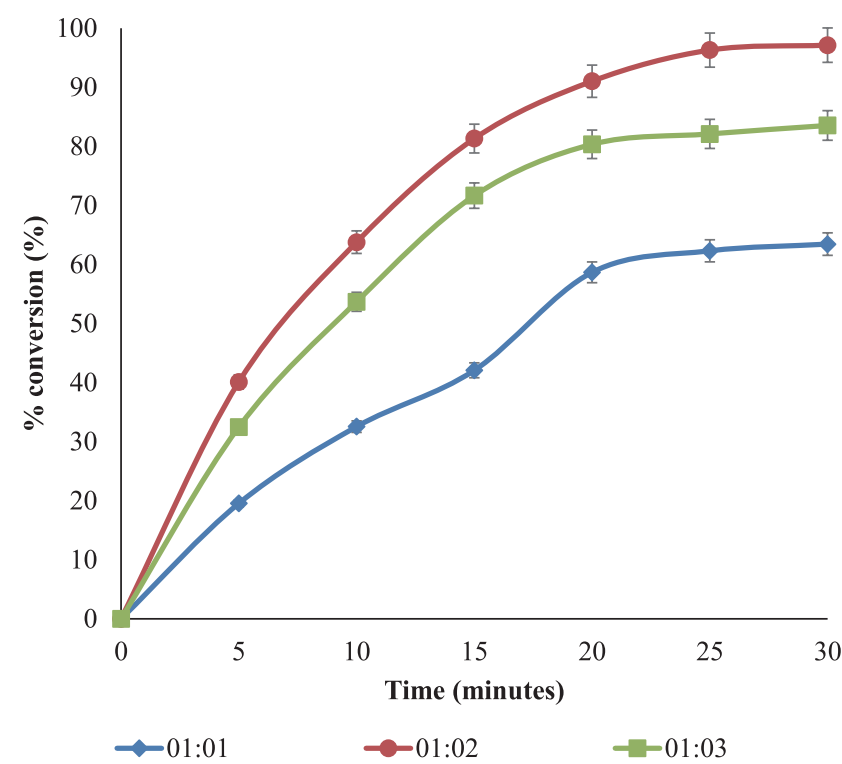

Fig. 4 Effect of molar ratio on conversion. Reaction condition: time- $25 \mathrm{~min}$, temperature $-45^{\circ} \mathrm{C}$, enzyme dose $1.8 \% \mathrm{w} / \mathrm{w}$, ultrasound power- $50 \mathrm{~W}$, ultrasound frequency- $22 \mathrm{kHz}$, speed of agitation$200 \mathrm{rpm} \&$ duty cycle- $50 \%$. 
enzyme. Thus, 1:2 oleic acid:decanol molar ratio gave maximum conversion, and the optimum ratio was used for further studies.

\subsection{Effect of agitation speed}

Since the reaction system is heterogeneous, i.e., solidliquid system in which reactants are present in the liquid form while the enzyme is in the solid-state, the speed of agitation plays an important role in overcoming the external mass transfer resistance. Hence, experiments were performed by changing the stirring speed from $100 \mathrm{rpm}$ to 250 rpm by keeping the other parameters constant. A gradual increase in the conversion from $63.57 \%$ to $97.61 \%$ was observed in Fig. 5, with an increase in agitation speed from $100 \mathrm{rpm}$ to $200 \mathrm{rpm}$, respectively. A maximum conversion of $97.61 \%$ was obtained at $200 \mathrm{rpm}$ speed. Thus, stirring speed along with ultrasonication has a notable influence on the percent conversion. The mechanical stirring, combined with ultrasound irradiation, is significantly needed for an effective mass transfer and consequent increase in percentage conversion $^{29)}$. Further, an increase in the speed of agitation to $250 \mathrm{rpm}$ reduced the percentage conversion. At a higher agitation speed, the enzyme lipase particles are projected off the reaction media on to the wall of the reactor, thereby reducing the amount of enzyme for the reaction. The enzyme lipase deactivation could also occur due to high shear and stress forces at higher agitation speed, which drops the percentage conversion ${ }^{26)}$. Thus, ultrasonication can provide more effective mass

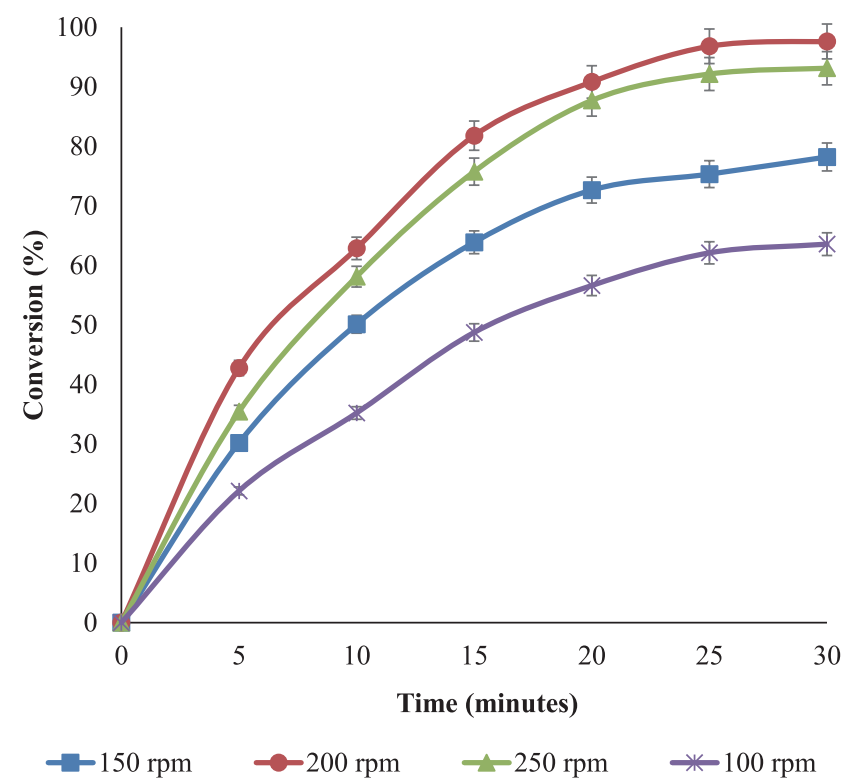

Fig. 5 Effect of agitation speed on conversion. Reaction condition: time- $25 \mathrm{~min}$, temperature- $45^{\circ} \mathrm{C}$, enzyme dose $1.8 \% \mathrm{w} / \mathrm{w}$, oleic acid:decyl alcohol ratio- $1: 2$, ultrasound power- $50 \mathrm{~W}$, ultrasound frequency- $22 \mathrm{kHz} \&$ duty cycle- $50 \%$. transfer at an optimum $200 \mathrm{rpm}$ to achieve maximum percentage conversion. Hence, $200 \mathrm{rpm}$ was chosen for the remaining reactions.

\subsection{Effect of duty cycle}

The duty cycle determines the economics of the method and also affects the percent conversion. The duty cycle represents a fraction of the time when the ultrasound system is operated. The ultrasound irradiation is advised to use with a definite duty cycle to minimize the likely disruption of the lipase conformation due to the prolonged contact of enzymes with ultrasound irradiation ${ }^{15)}$. The influence of the duty cycle on the synthesis of cosmetic value ester was analyzed by adjusting the ON-OFF time of the setup. Here, the impact of the duty cycle on percentage conversion was studied by varying it at 25\%,50\%, and $75 \%$. From Fig. 6, it is clear that with an increase in the duty cycle from $25 \%$ to $50 \%$, the percentage conversion increased from $64.01 \%$ to $97.8 \%$. However, a further increase in the duty cycle above $50 \%$ decreased the percentage conversion. Thus, the observed results showed the adequate stability of the immobilized enzyme up to $50 \%$ duty cycle. At the high percentage of duty cycle, a lower percentage conversion of the product was noticed because of the denaturation of the lipase as it was exposed to the ultrasound irradiation for prolonged time $\mathrm{e}^{30)}$. Similar results were observed at a higher duty cycle that changes the structure of the enzyme and causes denaturation ${ }^{16,21)}$. By using the optimum duty cycle of $50 \%$, the highest conver-

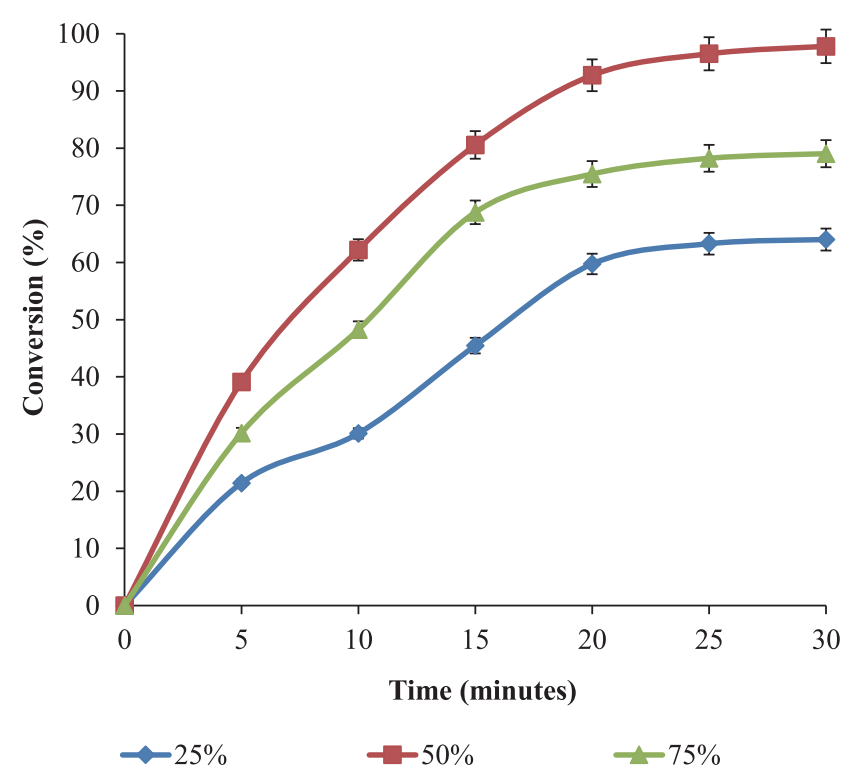

Fig. 6 Effect of duty cycle on conversion. Reaction condition: time- $25 \mathrm{~min}$, temperature- $45^{\circ} \mathrm{C}$, enzyme dose $1.8 \% \mathrm{w} / \mathrm{w}$, oleic acid:decyl alcohol ratio- $1: 2$, speed of agitation- $200 \mathrm{rpm}$, ultrasound power- $50 \mathrm{~W} \&$ ultrasound frequency- $22 \mathrm{kHz}$. 
sion of $97.8 \%$ was obtained in 25 minutes reaction time. Thus, the duty cycle was optimized to $50 \%$ and further used for the esterification reaction.

\subsection{Effect of power}

The intensity of cavitation depends on power and makes it an important parameter to study. The impact of ultrasound power was studied by changing the ultrasound power at $30 \mathrm{~W}, 40 \mathrm{~W}, 50 \mathrm{~W}$, and $60 \mathrm{~W}$. Figure 7 depicts that by increasing the power from $30 \mathrm{~W}$ to $50 \mathrm{~W}$, the percentage conversion improved from $58.78 \%$ to $97.66 \%$. Further increase in power reduced the conversion. The use of ultrasound irradiation in the liquid phase leads to the cavitation effect. As the power of ultrasound increases, the amount of cavitation bubbles produced in the system also increases, providing immense cavitational effects ${ }^{31}$. The ultrasound improves the synergy of the lipase and the reactant molecule, giving a higher rate of reaction. The energy produced because of the cavitation is carried to the reaction mass, which improves the mass transfer and diffusion of the reactants to the active enzyme site ${ }^{32)}$. Therefore, an increase in the percentage conversion of decyl oleate was observed until the $50 \mathrm{~W}$, and the reaction time was also decreased from $1 \mathrm{~h}$ to 25 minutes. The cavitational result produced due to ultrasound irradiation is affected by higher ultrasound power. Many bubbles are formed at a very high ultrasound power, but they coalesce together forming a large stable bubble. Thus, they produce a barrier and do not permit the smooth flow of ultrasound energy to the reac-

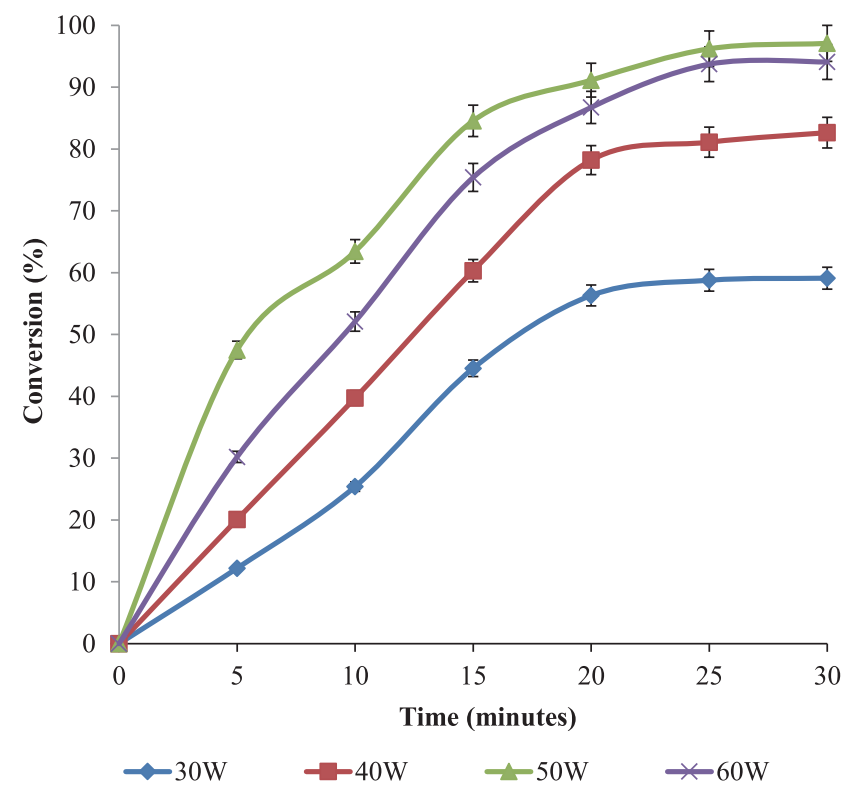

Fig. 7 Effect of power on conversion. Reaction condition: time- $25 \mathrm{~min}$, temperature- $45^{\circ} \mathrm{C}$, enzyme dose $1.8 \% \mathrm{w} / \mathrm{w}$, oleic acid:decyl alcohol ratio- $1: 2$, speed of agitation- $200 \mathrm{rpm}$, duty cycle- $50 \%$ \& ultrasound frequency- $22 \mathrm{kHz}$. tion medium, which leads to poor conversion ${ }^{17)}$. A similar trend for biodiesel synthesis was observed for power ranging from 100 to $200 \mathrm{~W}^{33)}$. Another possibility for minimal change at high power is the disruption of lipase conformation because of high cavitation intensity. It has been noted that moderate ultrasound power can improve the lipase activity, while ultrasound power beyond the optimum range can damage and denature the structure of enzymes $^{34)}$. It can be concluded that the optimum power of $50 \mathrm{~W}$ was chosen for the overall reaction.

\subsection{Effect of frequency}

After optimizing the power, we analyzed the frequency parameter affecting the conversion. In the current research study, the impact of ultrasound frequency for the decyl oleate synthesis was examined for $22 \mathrm{kHz}$ and $40 \mathrm{kHz}$. As seen from Fig. 8, a decrease in conversion was observed from $97.15 \%$ to $53.45 \%$ when the frequency increased from $22 \mathrm{kHz}$ to $40 \mathrm{kHz}$. This sharp decline in percentage conversion can be due to the reduction in shear forces and a reduction in the enzyme activity at a higher frequency ${ }^{35,36)}$. At a higher frequency, there is a chance of lipase disruption and deactivation. Thus, $22 \mathrm{kHz}$ was considered the optimum frequency for the reaction.

\subsection{Characterization of the product.}

The FT-IR spectra studied in the range of 500-3500 $\mathrm{cm}^{-1}$ are shown in Fig. 9. The band is seen in the FT-IR spectra

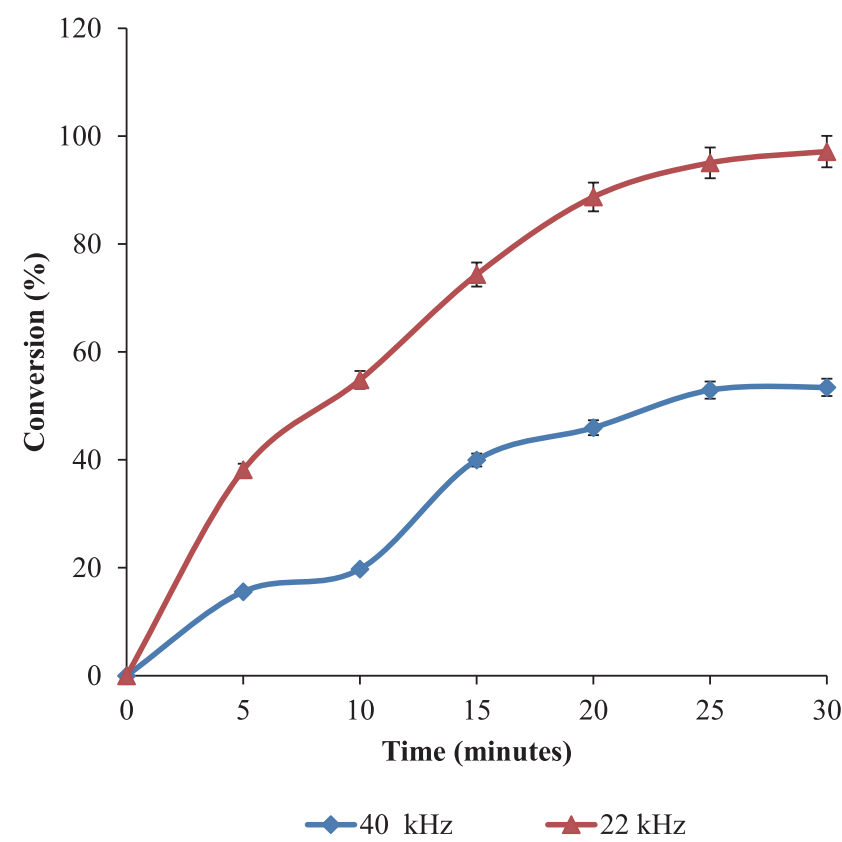

Fig. 8 Effect of frequency on conversion. Reaction condition: time- 25 min, temperature- $45^{\circ} \mathrm{C}$, enzyme dose $1.8 \% \mathrm{w} / \mathrm{w}$, oleic acid:decyl alcohol ratio- $1: 2$, speed of agitation- $200 \mathrm{rpm}$, ultrasound power- $50 \mathrm{~W}$, duty cycle- $50 \%$. 


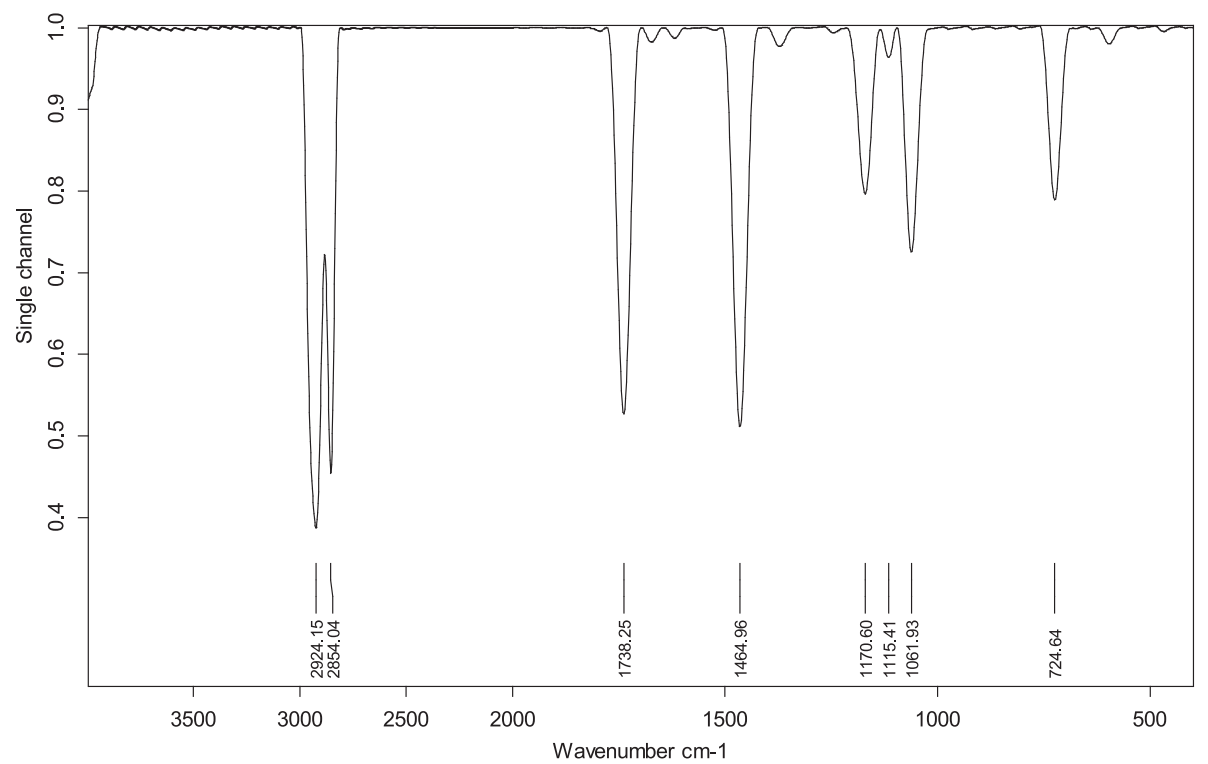

Fig. 9 FT-IR spectra of the product.

at $2924.15 \mathrm{~cm}^{-1}$ and $2854.04 \mathrm{~cm}^{-1}$ for alkane C-H stretching, while the peak at $1464.96 \mathrm{~cm}^{-1}$ is because of the stretching vibration of -C-H. The FT-IR spectrum also shows a peak at $1738.25 \mathrm{~cm}^{-1}$, which is due to the stretching of the carbonyl group stretching $(\mathrm{C}=\mathrm{O})$ that confirms the presence of ester group in the product.

\section{Reusability Study}

The reusability of enzyme lipase after each run plays an essential role in considering the economic profitability of biocatalytic synthesis. Hence, the reusability of the immobilized enzyme was carried out for the synthesis of decyl oleate. After every cycle, the immobilized enzyme and molecular sieves were separated from the reaction mass by filtration and washed multiple times using acetone. The washed enzyme and molecular sieves were then dried in an oven. The enzyme was separated from molecular sieves by physical separation, and the enzyme was then stored in the desiccator. The stored enzyme was finally used for the next cycle. The result obtained for the reusability of the enzyme for several cycles is shown in Fig. 10, which explains that the percentage conversion of decyl oleate decreases with each cycle. The percentage conversion for the first was $95.33 \%$, and for the fifth cycle was $76.14 \%$. The decrease in the percentage conversion can be because of the loss of enzyme activity through every cycle due to the continuous interaction of enzymes with ultrasound irradiation. During the esterification reaction, there may be physical damage to immobilization support and a change in the lipase structure in the presence of ultrasound ${ }^{16)}$. Thus, denaturation and breakage of the link between enzyme and the support is a likely reason for the drop in the lipase activity ${ }^{22)}$. Thus,

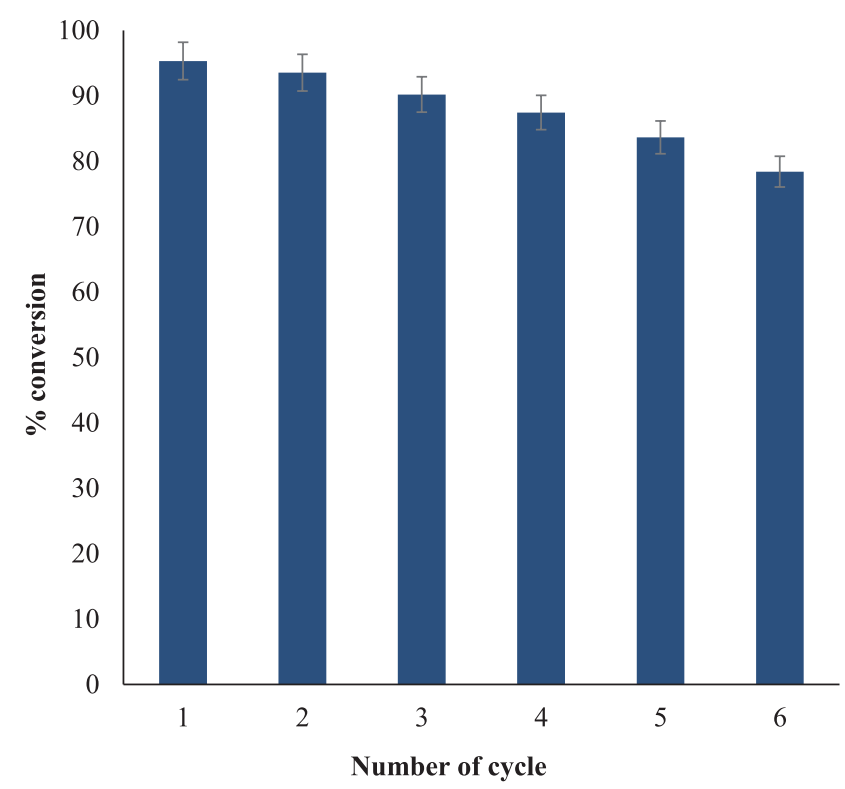

Fig. 10 Reusability study of lipase for decyl oleate synthesis. Reaction condition: time- $25 \mathrm{~min}$, temperature- $45^{\circ} \mathrm{C}$, enzyme dose $1.8 \% \mathrm{w} / \mathrm{w}$, oleic acid:decyl alcohol ratio- 1:2, speed of agitation$200 \mathrm{rpm}$, ultrasound power- $50 \mathrm{~W}$, duty cycle$50 \%$ \& ultrasound frequency- $22 \mathrm{kHz}$.

a reusability study revealed that lipase was adequately recycled and reused up to six cycles.

\section{Kinetic Study}

The kinetic study of a reaction is a fundamental perspective for the scale-up method. The literature reports several 
forms of bi substrate models, namely, order bi-bi, random bi-bi, or ping pong bi-bi models, which involve inhibition of one or both substrates ${ }^{17)}$. In the current kinetic modeling approach used to synthesize decyl oleate, different kinetic parameters were evaluated using the initial rate data. The equation for the given ordered bi-bi model is represented below, where the symmetrical mechanism obeys the order of attaching the substrate to the lipase and releases the two products in an ordered manner.

$$
v_{0}=\frac{V_{\max }[A][B]}{[A][B]+K_{B}[A]+K_{A}[B] K_{i A} K_{B}}
$$

In Random Bi-Bi model, the substrate attaches to the lipase in favored order and randomly releases the desired products. The initial rate equation is presented, as shown below:

$$
v_{0}=\frac{V_{\max }[A][B]}{[A][B]+K_{B}[A]+K_{A}[B] K_{i A} K_{B}}
$$

Ping-Pong Bi-Bi model is followed by the discharge of one or more products before the remaining substrate attaches the lipase. The initial rate equation is shown below:

$$
v_{0}=\frac{V_{\max }[A][B]}{[A][B]+K_{B}[A]+\left(1+[A] / K_{i A}\right)+K_{A}[B]\left(1+[B] / K_{i B}\right)}
$$

$v_{0}$ is the reaction rate, $\mathrm{V}_{\max }$ is the maximum rate of reaction, [A] is the initial concentration of decyl alcohol, [B] is the initial concentration of oleic acid, $\mathrm{K}_{A}$ is Michaelis constant for decyl alcohol, $\mathrm{K}_{B}$ is Michaelis constant for oleic acid, $\mathrm{K} i_{A}$, inhibition constant for decyl alcohol, and $\mathrm{K} i_{B}$ is the inhibition constant for oleic acid.

The kinetic parameters were analyzed by the non-linear regression analysis method with the least of the sum of square of errors (SSE) using Microsoft Excel 2016. The kinetic parameter values, as shown in Table 1, confirmed that the order bi-bi mechanism was suitably fitted and considered for the reaction. The maximum rate of reaction $\left(\mathrm{V}_{\text {max }}\right)$ shows the potential of the lipase to break from the lipase-substrate complex to form the desired product ${ }^{17)}$. The Michaelis-Menten constant $\left(\mathrm{K}_{A} / \mathrm{K}_{B}\right)$ value describes the affinity among lipase and substrates. The high capacity of

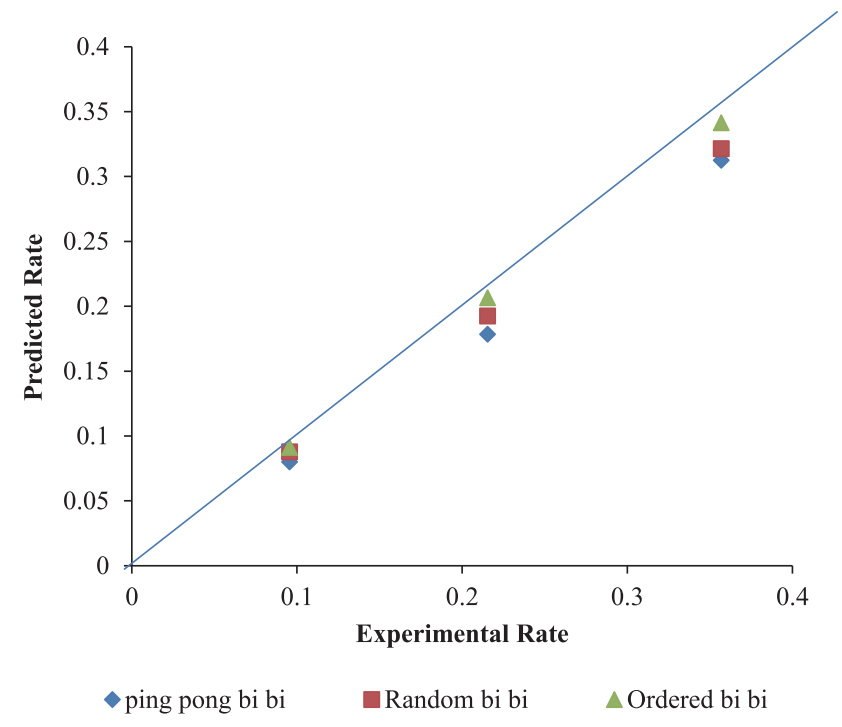

Fig. 11 Parity plot of predicted rate vs. experimental rate.

the reactant molecule to attach the lipase's non-catalytic positions causing the inhibition effect, is inferred by the inhibition constant $\left(\mathrm{K}_{i}\right)^{20)}$. The order bi-bi reveals the most suitable fit with kinetic parameters, $\mathrm{V}_{\max }=35.02 \mathrm{M} / \mathrm{min} / \mathrm{g}$ catalyst, $\mathrm{K}_{A}=34.47 \mathrm{M}, \mathrm{K}_{B}=3.31 \mathrm{M}, \mathrm{K}_{\mathrm{i}}=4542.4 \mathrm{M}$ and SSE $=0.000334$. Whereas the ping-pong bi-bi model and random bi-bi model produced unusually negative values that were unrealistic and therefore ruled out. Moreover, statistical parameters gave a minimal root mean square deviation and lowest SSE value for the order bi-bi mechanism, and it was proved that the reaction obeyed the order bi-bi model. The parity plot of the experimental versus theoretical initial rate for order bi-bi model gave the best correlation coefficient $\left(R^{2}=0.99\right)$, which exhibited that the suggested model was accurate for the given study, as shown in Fig. 11.

Table 1 Comparison table of kinetic parameter values for the decyl oleate synthesis.

\begin{tabular}{crcr}
\hline & \multicolumn{3}{c}{ Kinetic model } \\
\hline Parameters & Random bi-bi & Ping Pong bi-bi & Ordered bi-bi \\
\hline $\mathrm{V}_{\mathrm{m}}(\mathrm{M} / \mathrm{min} / \mathrm{g})$ & 21.01 & 91.12 & 35.02 \\
$\mathrm{~K}_{\mathrm{B}}(\mathrm{M})$ & 0.026 & $7.45 \times 10^{-4}$ & 3.31 \\
$\mathrm{~K}_{\mathrm{A}}(\mathrm{M})$ & -31.6 & -4.12 & 34.47 \\
$\mathrm{~K}_{\mathrm{iA}}(\mathrm{M})$ & 200.214 & $9.14 \times 10^{-1}$ & \\
$\mathrm{~K}_{\mathrm{i}}(\mathrm{M})$ & - & - & $4.54 \times 10^{3}$ \\
$\mathrm{SSE}$ & $1.8 \times 10^{-3}$ & $3.56 \times 10^{-3}$ & $3.34 \times 10^{-4}$ \\
\hline
\end{tabular}


Table 2 Energy of activation and thermodynamic parameter at different temperature.

\begin{tabular}{lcccc}
\hline & \multicolumn{5}{c}{ Temperature $(\mathrm{K})$} \\
\hline \multicolumn{1}{c}{ Parameter } & \multicolumn{1}{c}{303} & \multicolumn{1}{c}{308} & \multicolumn{1}{c}{313} & \multicolumn{1}{c}{318} \\
\hline Energy of activation, $\mathrm{Ea}(\mathrm{kJ} / \mathrm{mol})$ & \multicolumn{1}{c}{-} & \multicolumn{1}{c}{38.13} & \multicolumn{1}{c}{-} \\
Enthalpy change $(\Delta \mathrm{H}) \mathrm{kJ} / \mathrm{mol}$ & 35.61 & 35.57 & 35.53 & 35.49 \\
Entropy change $(\Delta \mathrm{S}) \mathrm{kJ} / \mathrm{mol} \mathrm{K}$ & -0.2683 & -0.2674 & -0.265 & -0.2631 \\
Free energy change $(\Delta \mathrm{G}) \mathrm{kJ} / \mathrm{mol}$ & 116.91 & 117.93 & 118.46 & 119.15 \\
\hline
\end{tabular}

Table 3 Physicochemical properties of decyl oleate.

\begin{tabular}{lcc}
\hline \multicolumn{1}{c}{ Property } & Decyl oleate & Jojoba oil \\
\hline Acid value & 0.5 & $<1$ \\
Saponification value & 60.5 & $90-95$ \\
Specific gravity & 0.860 & 0.863 \\
Spreading property $\left(\mathrm{mm}^{2}\right)$ & 790 & 840 \\
Viscosity $(\mathrm{cP})$ & 52.3 & 55.29 \\
Refractive index & 1.44 & 1.465 \\
Pour point & 6 & $7-10$ \\
\hline
\end{tabular}

\section{Thermodynamic Study}

The thermodynamic parameters for the enzyme-catalyzed synthesis of decyl oleate were estimated using the Eyring equation, as shown in Eq. 4 and 5.

$$
\begin{aligned}
& \operatorname{lnk}=\left[\frac{-E a}{R T}\right]+\ln A \\
& \ln \frac{k}{T}=\left[\frac{-\Delta H}{R}\right]\left[\frac{1}{T}\right]+\ln \frac{K_{B}}{h}+\frac{\Delta S}{R}
\end{aligned}
$$

Where h represents Planck's constant $\left(6.626 \times 10^{-34} \mathrm{J.s}\right)$, $\mathrm{K}_{B}$ is Boltzmann constant $\left(1.381 \times 10^{-23} \mathrm{~J} / \mathrm{K}\right), \mathrm{k}$ is the rate constant at temperature $\mathrm{T}, \Delta \mathrm{H}$ is the enthalpy of activation, $\Delta \mathrm{S}$ represent entropy of activation, $\mathrm{R}$ is the universal gas constant, and $\Delta \mathrm{G}$ is the Gibbs free energy.

The thermodynamic parameters, namely enthalpy $(\Delta \mathrm{H})$, entropy $(\Delta S)$, and Gibbs free energy $(\Delta G)$ were determined for the enzyme-catalyzed synthesis, as shown in Table 2. The negative entropy $(\Delta \mathrm{S}=-0.2674 \mathrm{~kJ} / \mathrm{mol} \mathrm{K})$ indicates that the product is highly ordered. The Gibbs free energy $(\Delta \mathrm{G})$ was estimated to be $118.46 \mathrm{~kJ} / \mathrm{mol}$ which showed that the esterification reaction is non-spontaneous. The enthalpy of the reaction $(\Delta \mathrm{H})$ was determined to be $35.53 \mathrm{~kJ} / \mathrm{mol}$, which indicates that outside heat is needed to transfer the reactants in the direction of the transition state. The temperature of the reaction has a significant impact on the reaction rate of ester synthesis because of the endothermic nature of the process ${ }^{37)}$. Hence, the optimum temperature is always recommended for the highest conversion.

\section{Determination of Physicochemical Properties of Decyl Oleate}

The synthesized wax ester was further used to determine its physicochemical properties such as saponification value, specific gravity, refractive index, flash point, pour point, spreading value, kinematic viscosity, etc. The wax ester properties were compared with jojoba oil, as shown in Table 3. The acid value of decyl oleate was only $0.5 \mathrm{mg}$ $\mathrm{KOH} \mathrm{g}^{-1}$, indicating a less harmful impact on the skin surface. Also, the saponification value shows a high molecular weight of wax ester. The viscosity of the decyl oleate is nearly equal to jojoba oil viscosity value due to the presence of the long carbon chain which makes it desirable for use in various creams. The waxy ester shows a low value of spreadability and pour point. The high value of the refractive index of the ester indicates a glossier finish ${ }^{38)}$.

\section{Conclusion}

Decyl oleate, a wax ester, is used prominently in the cosmetic industry, especially in skincare and beauty products. The ultrasound-assisted synthesis of decyl oleate using Fermase $\mathrm{CALB}^{\mathrm{TM}} 10000$ in the solvent-free system was carried out at different operating parameters. Under optimized condition, maximum conversion of $97.15 \%$ was achieved within 25 minutes at $45^{\circ} \mathrm{C}, 1: 2$ decyl alcohol to oleic acid ratio, $1.8 \%(\mathrm{w} / \mathrm{w})$ enzyme loading at $200 \mathrm{rpm}$ speed, $50 \%$ duty cycle, $40 \mathrm{~W}$ power, and $22 \mathrm{kHz}$ frequency. The potential use of ultrasound technique in the solventfree system substantially reduced the reaction time from 1 h to 25 minutes compared to the conventional method, which used hexane as solvent. The beauty market has been searching for newer production techniques that are environmentally friendly, sustainable, and cost-effective. The ultrasound intensification technique is a greener technology and hence a more attractive option to the cosmetic markets.

\section{Acknowledgement}

The authors are grateful to the University Grant Com- 
mission(UGC-SAP) for financial support.

\section{Conflict of Interest}

The authors declare no conflict of interest.

\section{References}

1) Deng, L.; Wang, X.; Nie, K.; Wang, F.; Liu, J.; Wang, P.; Tan, T. Synthesis of wax esters by lipase-catalyzed esterification with immobilized lipase from Candida sp. 99-125. Chin. J. Chem. Eng. 19, 978-982 (2011).

2) Khan, N.R.; Rathod, V.K. Enzyme catalyzed synthesis of cosmetic esters and its intensification: A review. Process Biochem. 50, 1793-1806 (2015).

3) Cheah, H.; May, C.; Zakaria, Z.; Daik, R. Synthesis of palmitic acid-based esters and their effect on the pour point of palm oil methyl esters. J. Oil Palm Res. 20, 542-547 (2008).

4) Jaiswal, K.S.; Rathod, V.K. Enzymatic synthesis of cosmetic grade wax ester in solvent free system: Optimization, kinetic and thermodynamic studies. $S N A p-$ plied Sciences 1, 949 (2019).

5) Rani, K.N.P.; Neeharika, T.S.; Kumar, T.P.; Satyavathi, B.; Sailu, C.H.; Prasad, R.B.N. Kinetics of enzymatic esterification of oleic acid and decanol for wax ester and evaluation of its physico-chemical properties. $J$. Taiwan Inst. Chem. E 55, 12-16 (2015).

6) Jaiswal, K.S.; Rathod, V.K. Green synthesis of amyl levulinate using lipase in the solvent free system: Optimization, Mechanism and Thermodynamics studies. Catal. Today doi.org/10.1016/j.cattod.2020.06.059 (2020).

7) Rocha, J.M.S.; Gil, M.H.; Garcia, F.A.P. Optimisation of the enzymatic synthesis of $n$-octyl oleate with immobilised lipase in the absence of solvents. J. Chem. Technol. Biotechnol. 74, 607-612 (1999).

8) Du, Y.; Gao, J.; Kong, W.; Zhou, L.; Ma, L.; He, Y.; Huang, Z.; Jiang, Y. Enzymatic synthesis of glycerol carbonate using a lipase immobilized on magnetic organosilica nanoflowers as a catalyst. ACS Omega 3, 6642-6650 (2018).

9) Graebin, N.G.; Martins, A.B.; Lorenzoni, A.S.G.; GarciaGalan, C.; Fernandez-Lafuente, R.; Ayub, M.A.Z. et al. Immobilization of lipase B from Candida antarctica on porous styrenedivinylbenzene beads improves butyl acetate synthesis. Biotechnol Prog. 28, 406-412 (2012).

10) Ortiz, C.; Ferreira, M.L.; Barbosa, O.; dos Santos, J.C.S.; Rodrigues, R.C.; Berenguer-Murcia, A.; Briand, L.E.; Fernandez-Lafuente, R. Novozym 435: The "perfect" lipase immobilized biocatalyst? Catal. Sci. Technol. 9,
2380-2420 (2019).

11) Du, Y.J.; Gao, J.; Zhou, L.Y.; Ma, L.; He, Y.; Huang, Z.H.; Jiang, Y.J. Enzyme nanocapsules armored by metal-organic frameworks: A novel approach for preparing nanobiocatalyst. Chem. Eng. J. 327, 1192-1197 (2017).

12) Gao, J.; Kong, W.X.; Zhou, L.Y.; He, Y.; Ma, L.; Wang, Y.; Yin, L.Y.; Jiang, Y.J. Monodisperse core-shell magnetic organosilica nanoflowers with radial wrinkle for lipase immobilization. Chem. Eng. J. 309, 70-79(2017).

13) Khan, N.R.; Jadhav, S.V.; Rathod, V.K. Lipase catalysed synthesis of cetyl oleate using ultrasound: optimisation and kinetic studies. Ultrason. Sonochem. 27, 522-529 (2015).

14) Colombié, S.; Tweddell, R.J.; Condoret, J.S.; Marty, A. Water activity control: A way to improve the efficiency of continuous lipase esterification. Biotechnol. Bioeng. 60, 362-368 (1998).

15) Homaei, A.A.; Sariri, R.; Vianello, F.; Stevanato, R. Enzyme immobilization: An update. J. Chem. Biol. 6(4), 185-205 (2013).

16) Khan, N.R.; Gawas, S.; Rathod, V.K. Enzyme-catalysed production of $n$-butyl palmitate using ultrasound-assisted esterification of palmitic acid in a solvent-free system. Bioprocess Biosyst. Eng. 41, 1621-1634 (2018).

17) Jaiswal, K.S.; Rathod, V.K. Acoustic cavitation promoted lipase catalyzed synthesis of isobutyl propionate in solvent free system: Optimization and kinetic studies. Ultrason. Sonochem. 40, 727-735(2018).

18) Martins, A.B.; Graebin, N.G.; Lorenzoni, A.S.G.; Fernandez-Lafuente, R.; Ayub, M.A.Z.; Rodrigues, R.C. Rapid and high yields of synthesis of butyl acetate catalyzed by Novozym 435: Reaction optimization by response surface methodology. Process Biochem. 46, 2311-2316 (2011).

19) Rezaei, K.; Jenab, E.; Temelli, F. Effects of water on enzyme performance with an emphasis on the reactions in supercritical fluids. Crit. Rev. Biotechnol. 27, 183-195 (2007).

20) Martins, A.B.; Schein, M.F.; Friedrich, J.L.R.; Fernandez-Lafuente, R.; Ayub, M.A.Z.; Rodrigues, R.C. Ultrasound-assisted butyl acetate synthesis catalyzed by Novozym 435: Enhanced activity and operational stability. Ultrason. Sonochem. 20, 155-1160 (2013).

21) Cui, F.J.; Zhao, H.X.; Sun, W.J.; Wei, Z.; Yu, S.L.; Zhou, Q.; Dong, Y. Ultrasound-assisted lipase catalyzed synthesis of D-isoascorbyl palmitate: Process optimization and kinetic evaluation. Chem. Cent. J. 7, 80 (2013).

22) Razdi, M.S.; Basri, M.; Salleh, A.B.; Ariff, A.; Mohammad, R.; Rahman, B.A. Rahman, R.N. High performance enzymatic synthesis of oleyl oleate using immobilised lipase from Candida antarctica. Electron. $J$. Biotechm. 8, 291-298(2005). 
23) Choudhury, H.A.; Malani, R.S.; Moholkar,V.S. Acid catalyzed biodiesel synthesis from Jatropha oil: Mechanistic aspects of ultrasonic intensification. Chem. Eng. J. 231, 262-272(2013).

24) Gawas, S.; Rathod, V.K. Enhancement in synthesis of ethyl laurate catalyzed by fermase by combined effect of ultrasound and stage wise addition of ethanol. Chem. Eng. Process 125, 207-213 (2018).

25) Yadav, G.D.; Devi, K.M. Enzymatic synthesis of perlauric acid using Novozym 435. Biochem. Eng. J. 10, 93101 (2002).

26) Khan, N.R.; Pratap, A. Green synthesis of isopropyl ricinoleate. J. Oleo Sci. 62, 153-158(2013).

27) Gawas, S.; Khan, N.R.; Rathod, V.K. Application of response surface methodology for lipase catalyzed synthesis of 2-ethylhexyl palmitate in a solvent free system using ultrasound. Braz. J. Chem Eng. 36, 10071017 (2019).

28) Geng, B.; Wang, M.; Qi, W. Cinnamyl acetate synthesis by lipase-catalyzed transesterification in a solvent-free system. Biotechnol. Appl. Biochem. 59, 270-275 (2012).

29) Paludo, N.; Alves, J.S.; Altmann, C.; Ayub, M.A.; Fernandez-L, R.; Rodrigues, R.C. The combined use of ultrasound and molecular sieves improves the synthesis of ethyl butyrate catalyzed by immobilized thermomyces lanuginosus lipase. Ultrason. Sonochem. 22, 89-94 (2014).

30) Cerveró, J.M.; Álvarez, J.R.; Luque, S. Novozym 435-catalyzed synthesis of fatty acid ethyl esters from soybean oil for biodiesel production. Biomass Bioen- ergy 61, 131-137(2014).

31) Eisenberg, P. Cavitation. in Handbook of Fluid Mechanics. Tata McGraw Hill Publications. Chapter-12 (2009).

32) Sutkar, V.S.; Gogate, P.R. Design aspects of sonochemical reactors: Techniques for understanding cavitational activity distribution and effect of operating parameters. Chem. Eng. J. 155, 26-36 (2009).

33) Ji, J.; Wang, J.; Li, Y.; Yu, Y.; Xu, Z. Preparation of biodiesel with the help of ultrasonic and hydrodynamic cavitation. Ultrasonics 44, 411-414(2006).

34) Sinisterra, J.V. Application of ultrasound to biotechnology: An overview. Ultrasonics 30, 180-185(1992).

35) Lee, S.H.; Nguyen, H.M.; Koo, Y.M.; Ha, S.H. Ultrasound-enhanced lipase activity in the synthesis of sugar using ionic liquid. Process Biochem. 43, 1009-1012 (2008).

36) Cenia, G.; Silva, P.C.; Lerin, L.; Oliveira, J.V.; Toniazzo, G.; Treichel, H.; Oestreicher, E.G.; Oliveira, D.L. Ultrasound-assisted enzymatic transesterification of methyl benzoate and glycerol to 1-glyceryl benzoate in organic solvent. Enzyme Microb. Technol. 48, 169-174 (2011).

37) Lima, L.C.D.; Peres, D.G.C.; Mendes, A.A. Kinetic and thermodynamic studies on the enzymatic synthesis of wax ester catalyzed by lipase immobilized on glutaraldehyde-activated rice husk particles. Bioprocess Biosyst. Eng. 41, 991-1002 (2018).

38) Wisniak. The chemistry and technology of jojoba oil. AOCS Press, USA (1987). 